\title{
Técnica para marimba: um estudo dirigido às principais formas de se posicionar quatro baquetas nas mãos
}

\author{
ELIANA C. M. GUGLIELMETTI SULPICIO
}

Eliana C. Maggioni Guglielmetti Sulpicio é natural de Ribeirão Preto e iniciou seus estudos musicais aos seis anos de idade através do piano. Doutora em musicologia pela ECA-USP, mestre pela Boston University (EUA), bacharel em percussão pelo IA-UNESP de São Paulo e graduada em piano pela UNAERP; estudou também na Escola Municipal de Música de São Paulo. Atuou em diversas orquestras no Brasil e no exterior tais como: Orquestra Sinfônica de Ribeirão Preto; Orquestra Filarmônica de São Caetano do Sul; Banda Sinfônica do Estado de São Paulo; Orquestra Filarmônica de São Bernardo do Campo; Orquestra Sinfônica de Santos; Bachiana Filarmônica; Orquestra Sinfônica do Estado de São Paulo (artista convidada), Civic Symphony of Boston, Newton Philharmonic, Plymouth Orchestra, New England Philharmonic Orchestra, Boston University Symphony Orchersta, Boston University Wind Ensemble, Boston University Percussion Ensemble, sob regência de Thomas Gauger; Alea III (grupo de música contemporânea em residência na Boston University). Foi professora da GYBSO (Greater Youth Boston Symphony Orchestra), da Faculdade Paulista de Artes e de festivais de música em Brasília, llha Solteira, Mauá, Bragança Paulista e República Dominicana. Estudou composição com Almeida Prado, Samuel Headrick e Lucas Foss. Possui várias obras para percussão, sendo uma delas premiada no concurso nacional "Hildegard Soboll Martins" da Universidade Federal do Paraná. Atua frequentemente em música de câmara com o In Tempori Duo, formado desde 1994, com o trompetista Carlos Sulpício, é professora do Departamento de Música da Universidade de São Paulo em Ribeirão Preto, integrante do Ensemble Mentemanuque, diretora artística e regente do GRUPURI, Grupo de Percussão do Curso de Música da FFCLRP-USP.

Email: elianasulpicio@usp.br 


\title{
- RESUMO
}

Como parte do resultado apresentado na tese de doutorado $\mathrm{O}$ desenvolvimento da técnica de quatro baquetas: dos primórdios às primeiras composições brasileiras (SULPICIO, 2011), no presente artigo apresentamos as diferentes formas de se segurar quatro baquetas, uma das técnicas empregadas para a execução da Marimba. Através da revisão da literatura atual, predominantemente norte-americana, que trata do assunto, elucidamos com detalhes os procedimentos desta técnica e propomos uma tabela final contendo todas essas formas de se posicionar quatro baquetas nas mãos.

\section{- PALAVRAS-CHAVE}

Marimba, performance, técnica de quatro baquetas.

\begin{abstract}
As part of the results presented in the doctoral thesis The development of four mallets technique: from the early days to the first Brazilian compositions (SULPICIO, 2011), this article presents the different ways to hold four mallets, which is one of the techniques employed for Marimba playing. By reviewing the current literature that deals with it, predominantly from the United States of America, we elucidate in detail the procedures related to this technique and propose a final table containing all current grips.
\end{abstract}

\section{KEYWORDS}

Marimba, performance, technique for four mallets.

\section{Introdução}

Os teclados de percussão são idiofones pertencentes ao grupo dos instrumentos da percussão, cujos sons são resultantes da vibração do próprio corpo do instrumento, não necessitando de tensão tais como cordas ou membranas. Dentre estes tipos específicos de idiofones, temos a marimba, o xilofone, o glockenspiel e o vibrafone e, na literatura brasileira, encontramos o termo barrafones ${ }^{1}$ usado por alguns autores para se referirem a estes instrumentos.

De acordo com Merrill (1996, p.1), existem quatro fatores que tornam o som da marimba atual característico. $\mathrm{O}$ primeiro diz respeito à maneira como as teclas são construídas. Geralmente as marimbas são construídas com uma madeira chamada "pau rosa" e diferentemente das teclas do xilofone, são mais longas e mais amplas, possuindo um formato cavado na parte de baixo da tecla, o que lhe dá uma característica de lâmina. O segundo fator está relacionado ao processo de afinação destas teclas, processo este ditado pelos formatos que as teclas devem adquirir. No som emitido pela marimba, o harmônico mais significante é o que se encontra duas oitavas acima da fundamental, ou seja, o quarto harmônico (Figura 1.1).

O terceiro fator envolve os ressonadores, que são longos tubos de metal usados para amplificar e intensificar os sons das teclas e não para prolongá-los, como muitos acreditam. Finalmente, o quarto fator é determinado pela escolha dos tipos de baquetas a serem usadas.

\footnotetext{
${ }_{1}$ Barrafones: termo empregado por alguns autores, como Luiz D'Anunciação e Ney Rosauro que corresponde aos teclados de percussão.
} 


\section{harmônico predominante}

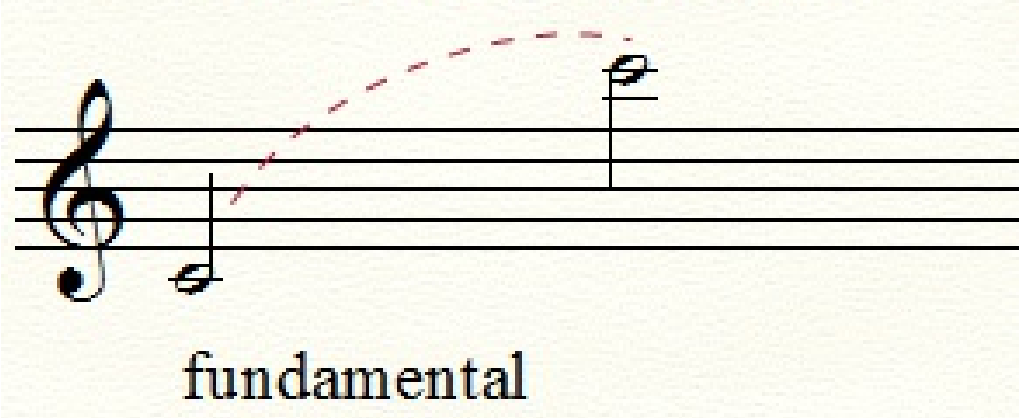

Figura 1.1. Fundamental e harmônico predominante na marimba. ${ }^{2}$

As extensões empregadas nas marimbas podem variar de quatro oitavas até cinco oitavas. A figura abaixo (Figura 1.2) mostra um instrumento moderno com a extensão de quatro oitavas e um terço (Figura 1.3).

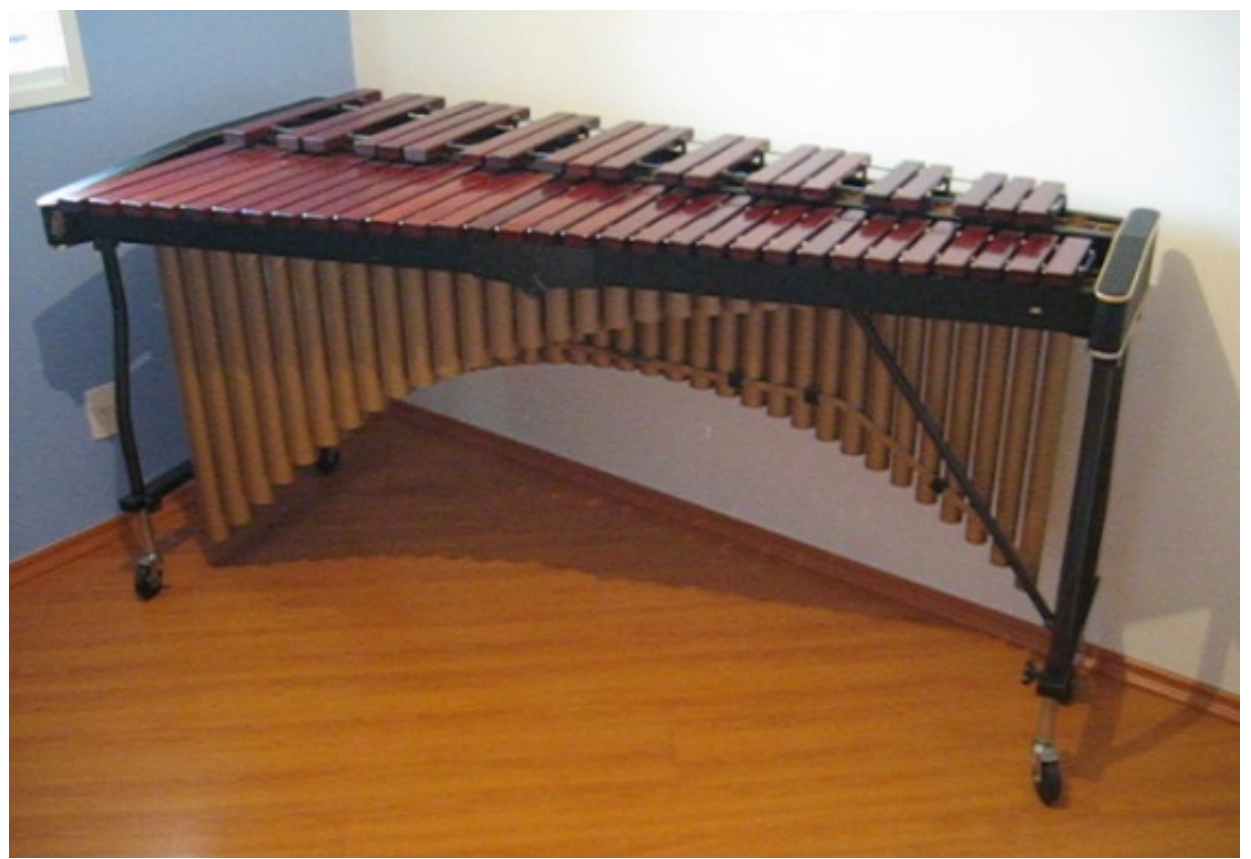

Figura 1.2. Marimba da marca Kori construída nos anos noventa do século passado. Exemplar com a extensão de quatro oitavas e um terço, teclas de madeira "pau rosa" e tubos de metal. Fonte: da autora.

\footnotetext{
${ }^{2}$ No caso do xilofone, o harmônico mais perceptível é o que se localiza uma oitava e uma quinta acima da fundamental, ou seja, o terceiro harmônico.
} 


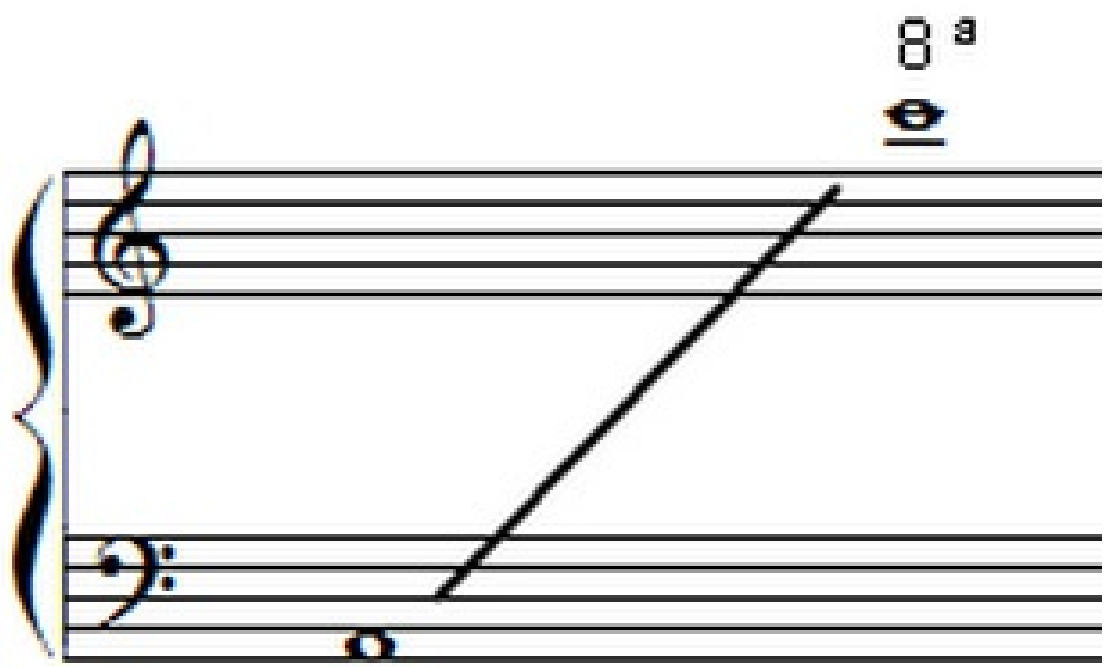

Figura 1.3. Extensão do instrumento exemplificado na figura 2.3.

Para a execução destes teclados de percussão, emprega-se em termos gerais a técnica de duas baquetas para o xilofone e glockenspiel e a técnica de quatro baquetas para a marimba e para o vibrafone ${ }^{3}$.

\section{Os diferentes grips utilizados}

Em meio à bibliografia existente há a descrição destes posicionamentos para se segurar duas baquetas em cada mão. Para isso, a palavra de uso corrente é o termo grip. Pela dificuldade em encontrar uma palavra adequada em português, que contenha em sua essência a tradução apropriada para o termo em questão, optamos por manter o conceito de grip. Este termo (ato de segurar) serve tanto para especificar a maneira usada para se segurar uma baqueta em cada mão, como também para especificar a maneira como duas baquetas são posicionadas na mão. Porém, lembramos ainda que se utiliza o termo "pinça" em português de modo diferenciado para especificar a maneira como uma baqueta é presa entre o dedo polegar e o indicador. De acordo com Tarcha, "pinça é a maneira usada para segurar a baqueta. Em inglês, grip, termo de uso corrente entre os percussionistas - quase sempre na técnica de quatro baquetas -, para designar a maneira de segurar duas baquetas em cada mão" (TARCHA, 1997, p.8). Ou seja, grip é a maneira como seguramos as quatro baquetas, é o posicionamento inicial, o ponto de partida para a técnica como um todo.

Apresentamos a seguir as diferentes maneiras de se posicionar duas baquetas em cada mão, no entanto, não advogamos em prol de uma ou outra, dentre as maneiras aqui apontadas. Acreditamos que esta escolha depende da idiossincrasia de cada indivíduo, tais como tamanho e musculatura das mãos, preferência

${ }^{3}$ Ambas as técnicas podem ser empregadas em todos os teclados de percussão, sendo o mais usual o citado acima. 
de baquetas, tipo de teclado de percussão a ser tocado, estilo do repertório e afinidades gerais inerentes a cada um.

Para o reconhecimento das baquetas nos diferentes grips, utilizaremos a seguinte numeração ${ }^{4}$ (Figura 2.1):

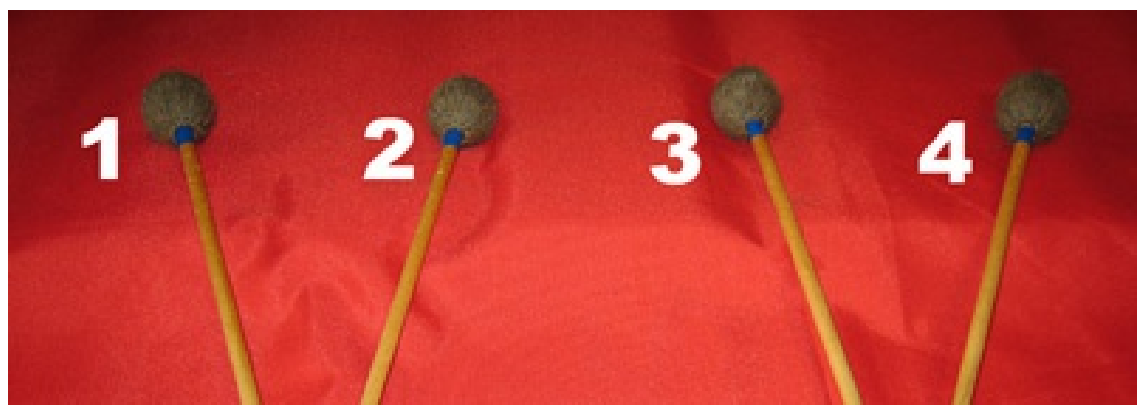

Figura 2.1. Da esquerda para a direita, baquetas 1-2-3-4. As baquetas 1 e 2 ficam na mão esquerda e as baquetas 3 e 4 na mão direita. Fonte: da autora.

Para as ilustrações dos diferentes grips serão apresentados exemplos com a mão direita, uma vez que em todos os grips, a mão esquerda, em termos de posicionamento das baquetas, procede exatamente igual à direita. Para os dedos, tal como no caso do piano, utilizaremos a seguinte numeração (Figura 2.2):

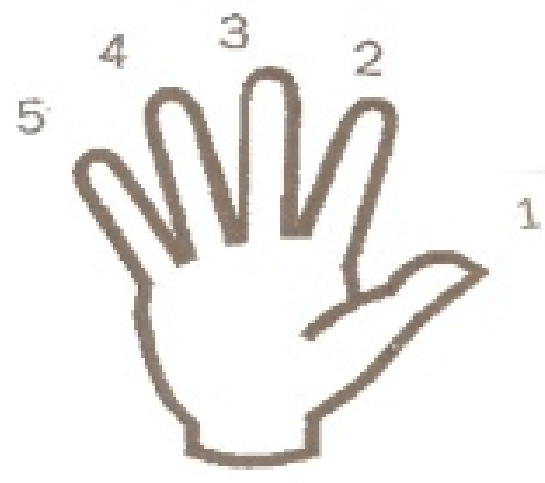

Figura 2.2. Indicação da numeração dos dedos.

Os termos Crossed grips e Uncrossed grips serão também utilizados ao longo do texto. Neste caso, em alguns momentos, também optamos pela conservação do uso dos termos em inglês, sendo que o termo Crossed grip significa que os cabos das baquetas se cruzam na palma da mão (cabos cruzados) e o termo Uncrossed grip significa que os cabos das baquetas não se cruzam na palma da mão (cabos não cruzados).

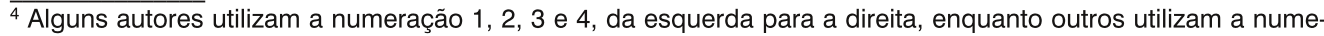
ração contrária 4, 3, 2, e 1, da esquerda para a direita. 
A seguir, apresentamos os grips com explicações detalhadas na visão de cada autor consultado.

A respeito deste assunto, Howarth ${ }^{5}$ (2002, p. 6) afirma:

Existem várias maneiras de se segurar duas baquetas em uma mão, o que implica na existência de vários grips. Todos esses possíveis grips podem ser colocados dentro de duas categorias: Uncrossed grips e Crossed grips (HOWARTH, 2002, p. 6).

De acordo com Howard na categoria do Crossed grip encontram-se:

1. Tradicional/Scissor ${ }^{6}$ grip

2. Burton grip

3. Stout grip

Dentro da categoria Uncrossed grip encontram-se:

1. Musser grip

2. Stevens grip

Zeltsman ${ }^{7}$ (2003, p.2) também faz uma primeira divisão destes grips em duas categorias:

1. Cross grips:

1.1. Tradicional grip

1.2. Burton grip

2. Independent-mallet grip ${ }^{8}$ :

2.1. Musser grip

2.2 Stevens grip

Stevens (1979, p.8) faz uma separação dos diferentes grips em três categorias:
1. Tradicional grip
2. Burton grip
3. Musser grip

Stevens completa com a seguinte informação:

O Tradicional grip e o Burton grip são frequentemente descritos como Crossed-stick (cabos cruzados) ou grips dependentes, pelo fato dos cabos das baquetas se cruzarem na palma da mão. O Musser grip é também descrito como grip independente, pelo fato dos cabos das baquetas serem segurados em partes separadas da mão e nunca entrarem em contato um com o outro (STEVENS, 1993, p.8).

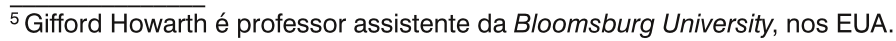

${ }^{6}$ Scissor em inglês = tesoura. Recebe este nome, por lembrar uma tesoura.

${ }^{7}$ Nancy Zeltsman é professora do Boston Conservatory e da Berklee College of Music, nos EUA.

${ }^{8} \mathrm{~A}$ autora se refere à Uncrossed Grip como Independent-mallet grip pelo fato dos cabos das baquetas não entrarem em contato um com o outro, sendo segurados em partes independentes das mãos.
} 
Kostowa/Giesecke ${ }^{9}$ (1996, p.7) demonstram a seguinte divisão:

1. Cross-grip techniques:

1.1. Tradicional grip ou Delecluse grip

1.2. Burton/Friedman/Samuels grip

1.3. Gordon-Stout grip

\section{Non-crossing grips:}

\subsection{Musser grip \\ 2.2. Stevens grip \\ 2.3. Maineri grip}

Para Mitchell Peters ${ }^{10}$ (s.d., p.114) existem diversas maneiras de se posicionar quatro baquetas, sendo os mais comuns e usados atualmente os seguintes grips:
1. Musser-Stevens grip
2. Burton grip
3. Tradicional cross-grip

Glassock ${ }^{11}$, num artigo para a Percussive Notes (1973), escreve que existem três métodos básicos de se segurar quatro baquetas.

1. Musser grip

2. Cross stick n. 1 (referindo-se à Burton grip, no entanto, não menciona este termo).

3. Cross stick n. 2 (referindo-se à Tradicional grip, mas também não mencionado este termo).

Burton, em seu método Four Mallet Studies, escreve sobre as possibilidades de se segurar quatro baquetas:

Existem poucas possibilidades para se segurar quatro baquetas nas mãos. Muitos executantes declaram usar seus próprios métodos. Eu não sou exceção. Portanto, para melhor analisar este assunto confuso, deixe-nos considerar os detalhes dos aspectos físicos e mecânicos envolvidos. No uso de quatro baquetas importa a liberdade de movimento em abrir e fechar as baquetas. Também deve ser mencionada a troca com facilidade para o uso de duas baquetas, enquanto se toca com quatro baquetas segurando as outras duas à parte. Por outro lado, somente duas baquetas são usadas para passagens lineares. Consequentemente, será sempre desejável qualquer método que resulte num número mínimo de movimentos para se segurar as baquetas. $E$ isto vale para os pulsos, braços e baquetas. $O$ método deve sempre propiciar uma melhor estabilidade em controlar as baquetas (BURTON, 1995, p.3).

\footnotetext{
${ }^{9}$ Wessela Kostowa, nascida na Bulgária, solista com inúmeras gravações. Mark Andreas Giesecke é alemão, solista, compositor, é membro do Kostowa-Giesecke Duo ao lado de Wessela Kostowa.

${ }_{10}$ Mitchell Peters é professor da University of California, Los Angeles, EUA.

${ }^{11}$ Lynn Glassock é professor assistente da California State University, Fresno, EUA. 


\subsection{Tradicional grip}

É o grip para o uso de quatro baquetas mais antigo. No Tradicional grip os cabos das baquetas são cruzados na palma da mão, com o cabo da baqueta que fica do lado de fora embaixo do cabo da baqueta que fica do lado de dentro. Ou seja, os cabos das baquetas 2 e 3 passam por cima dos cabos das baquetas 1 e 4 .

De acordo com Zeltsman (2003, p.3), os dedos 4 e 5 passam em torno dos cabos das baquetas, mantendo as baquetas juntas ao cabo da baqueta de fora por baixo. Os dedos 4 e 5 precisam alongar-se através das baquetas, curvando-se e tocando a palma da mão.

O quinto dedo (e às vezes o quarto dedo também) quase sempre tocará a palma de sua mão e algumas vezes ele precisará segurar os cabos das baquetas firmemente. Se você possui dedos longos, poderá ajudar pensar em deixar seu quarto e quinto dedos posicionados de forma mais estendida sobre os cabos das baquetas ao invés de curvá-los sobres os cabos. Isto evitará que as unhas do quarto e quinto dedos toquem de forma desconfortável sobre a palma da mão. [...] O seu primeiro e segundo dedo estarão sempre entre as duas baquetas. [...] O terceiro dedo, gentilmente sustenta a baqueta de fora. Você deve manter o terceiro dedo levemente curvado todo o tempo. Se ele se curva de forma muito rígida, impedirá você de juntar as duas baquetas para tocar intervalos pequenos. [...] O polegar deverá repousar sobre o cabo da baqueta de dentro. É importante curvar levemente o polegar para visualizar melhor a definição das juntas. Existem dois pontos importantes a serem considerados quanto à parte externa do polegar em relação à baqueta interna. (1) logo acima da primeira junta: que é entre a unha e a primeira junta; (2) logo abaixo da primeira junta (ZELTSMAN, 2003, p.3 e 6).

As figuras de número 2.1.1 a 2.1.9 mostram Zeltsman com o uso do Tradicional grip:

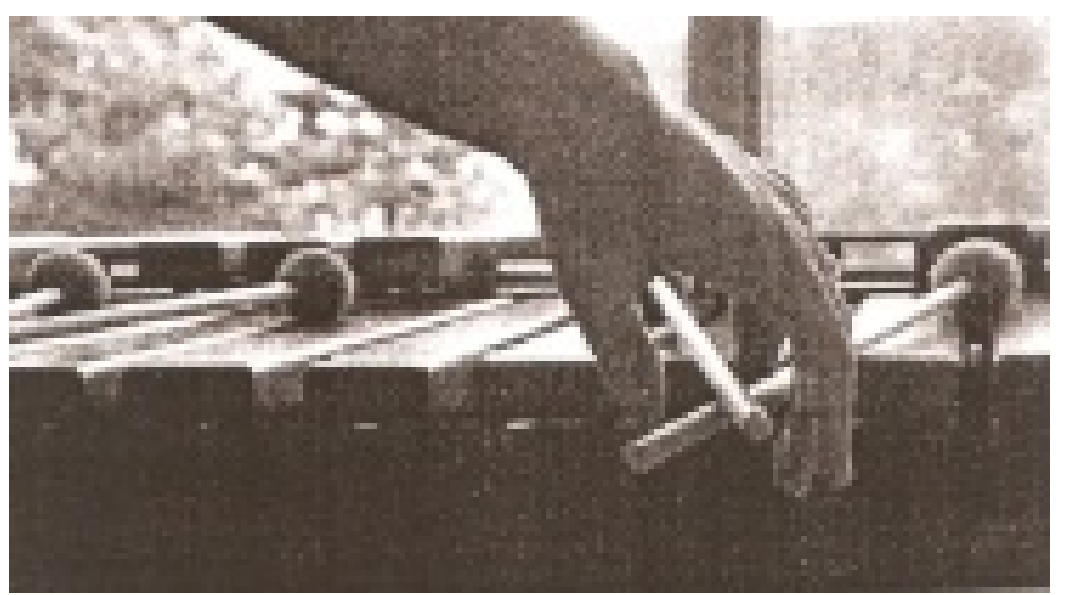

Figura 2.1.1. Tradicional grip. Fonte: Zeltsman (2003, p. 3). 


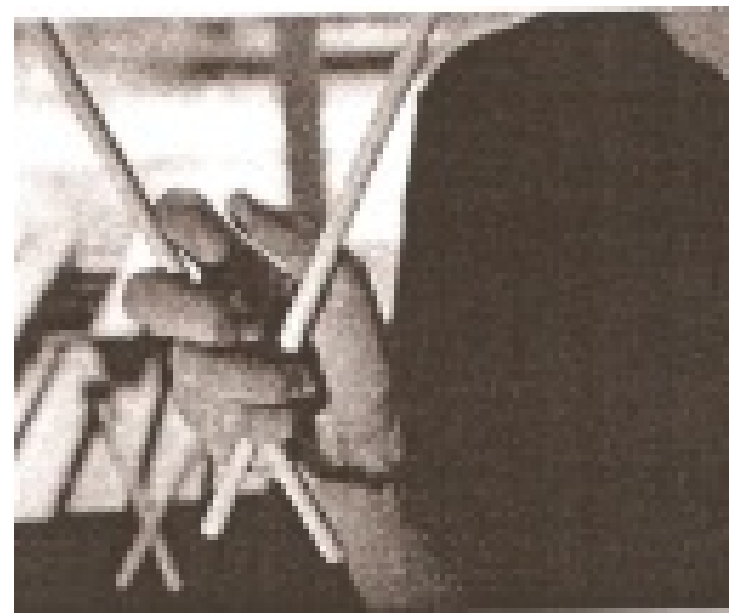

Figura 2.1.2. Tradicional grip. Fonte: Zeltsman (2003, p. 3).

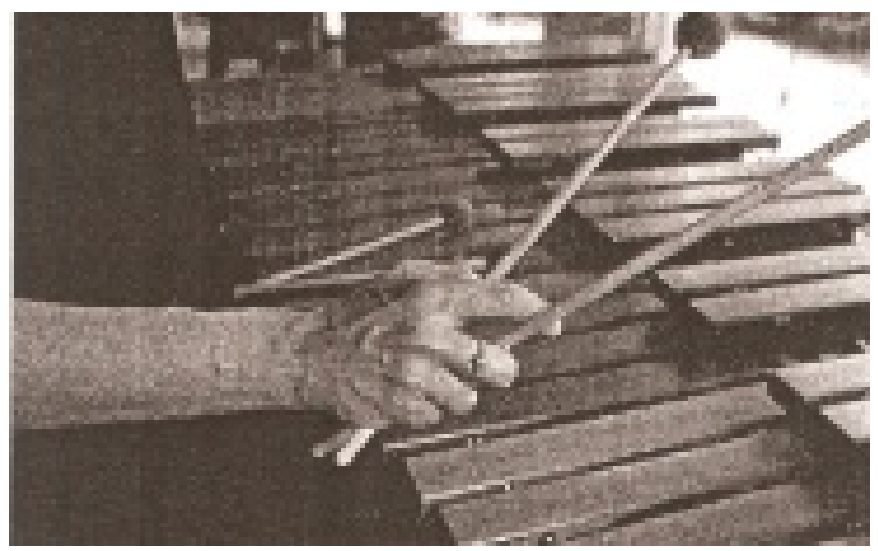

Figura 2.1.3. Tradicional grip. Fonte: Zeltsman (2003, p. 3).

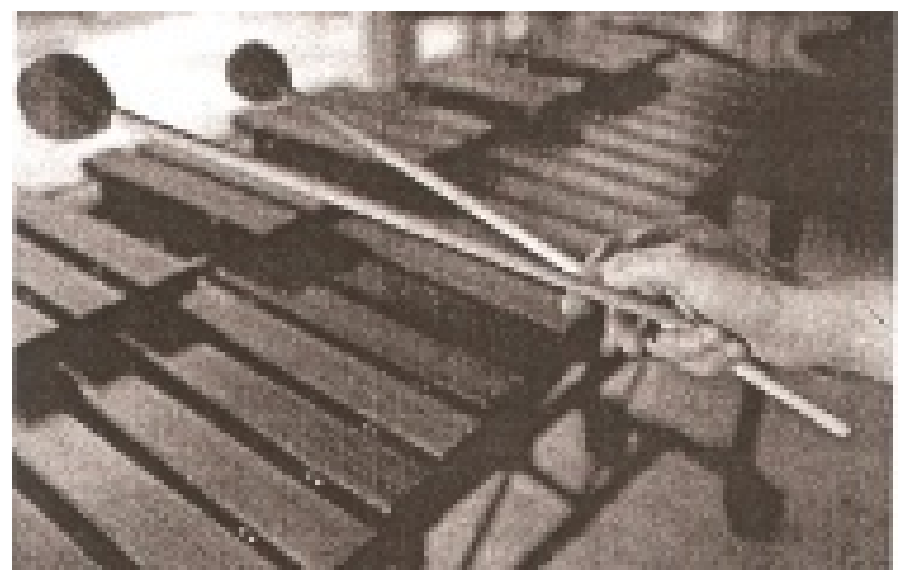

Figura 2.1.4. Tradicional grip. Fonte: Zeltsman (2003, p. 4). 


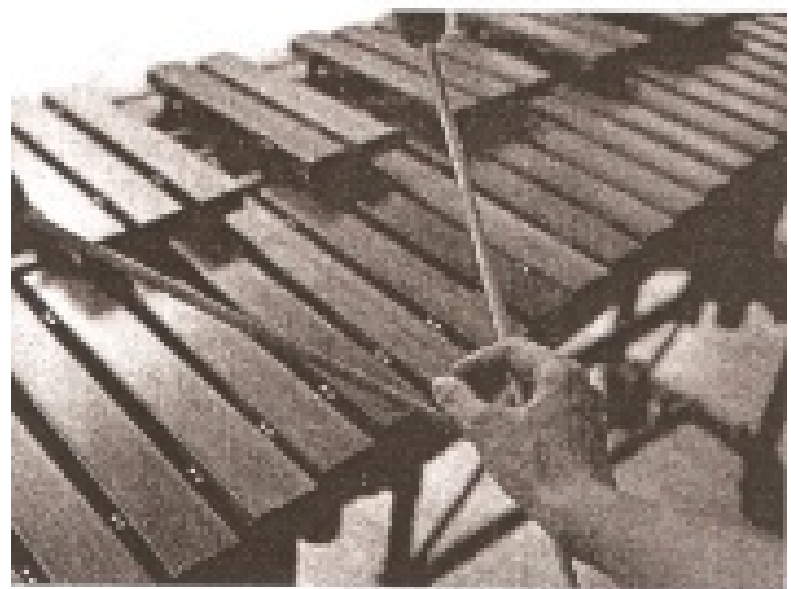

Figura 2.1.5. Tradicional grip. Fonte: Zeltsman (2003, p. 4).

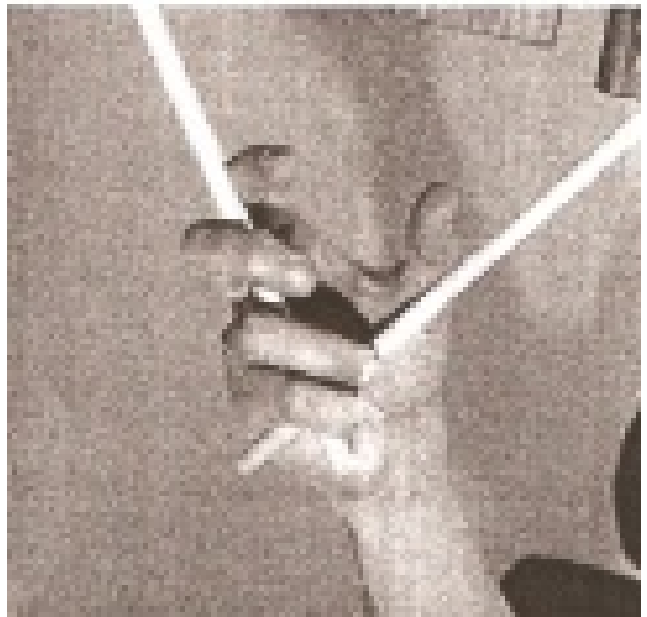

Figura 2.1.6. Tradicional grip. Fonte: Zeltsman (2003, p. 4).

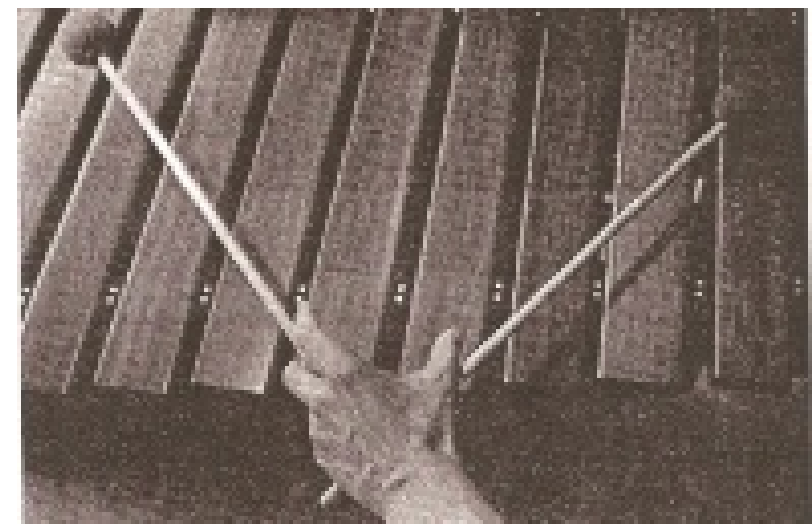

Figura 2.1.7. Tradicional grip. Fonte: Zeltsman (2003, p. 6). 


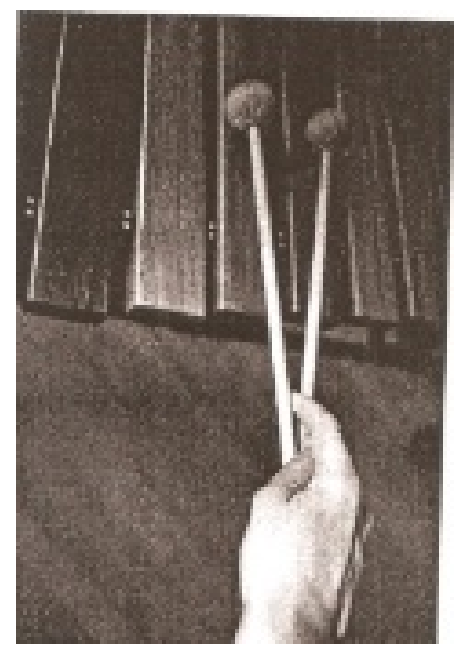

Figura 2.1.8. Tradicional grip. Fonte: Zeltsman (2003, p. 7).

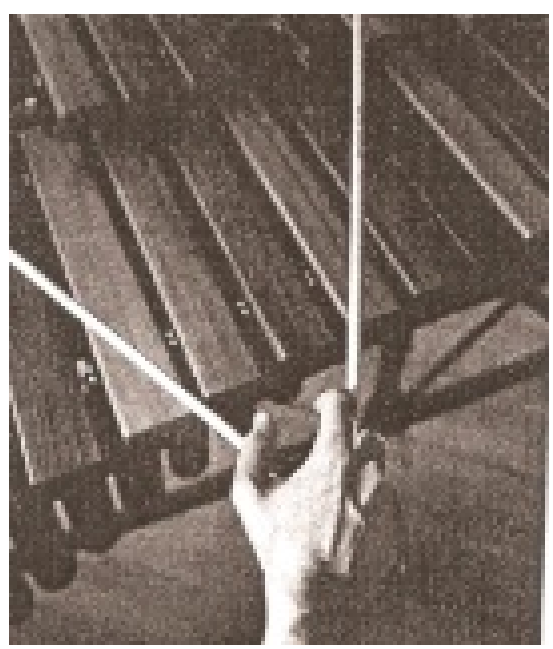

Figura 2.1.9. Tradicional grip. Fonte: Zeltsman (2003, p. 7).

Zeltsman aponta seis pontos considerados importantes e que podem justificar as vantagens deste grip: 1. Possibilita uma boa alavanca; 2. Dá sensação de segurança; 3. Com este grip é mais fácil segurar baquetas mais pesada; 4 . Movimentos mais fáceis; 5 . Maior variedade de articulação; 6 . Oferece tanta potência quanto os outros grips. ${ }^{12}$

\subsection{Burton Grip}

Dentro da categoria do crossed grip, o Burton grip é um dos mais populares e foi desenvolvido pelo legendário vibrafonista Gary Burton (HOWARTH, 2002, p.36).

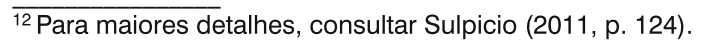


Burton utiliza o grip que se tornou mundialmente conhecido com o seu nome. Os cabos das baquetas são cruzados na palma da mão de forma contrária ao tradicional grip, ou seja, o cabo da baqueta que fica do lado de fora fica acima do cabo da baqueta que fica do lado de dentro. Portanto, o cabo da baqueta 1 passa por cima do cabo da baqueta 2. Já o cabo da baqueta 4 passa por cima do cabo da baqueta 3, ficando os cabos das baquetas 1 e 4 mais próximos à palma da mão.

Em seu livro Four Mallet Studies, Burton esclarece sua preferência por este grip:

Minha preferência é para o seguinte grip, o qual não é amplamente usado. Minhas justificativas para isso são as seguintes: 1) Na mão direita, a baqueta que fica do lado de fora irá sempre atuar na parte da melodia e não mudará suas funções constantemente. 2) $O$ movimento de percutir é sempre para cima e para baixo tanto com duas ou quatro baquetas. 3) Com o posicionamento adequado das baquetas que não estão sendo utilizadas, não existe movimento excessivo da baqueta que não está sendo usada para as execuções de passagens com duas baquetas. 4) A segunda baqueta está numa posição onde ela pode facilmente ser usada como suporte harmônico adicional da linha melódica quando desejado, sem necessitar que a baqueta de cima mude sua função. 5) Este grip oferece segurança e controle das baquetas com os dedos (BURTON, 1995, p.4).

As figuras 2.2.1 a 2.2.6, extraídas de seu livro Four Mallet Studies (1995), ilustram o Burton grip:

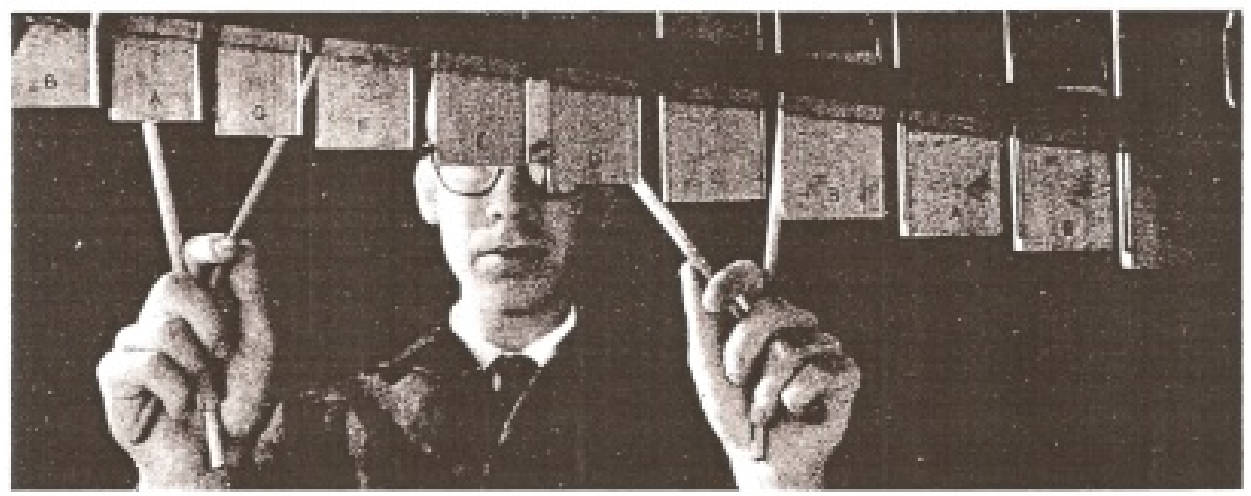

Figura 2.2.1. Burton grip. Fonte: Burton (1995, p. 4). 


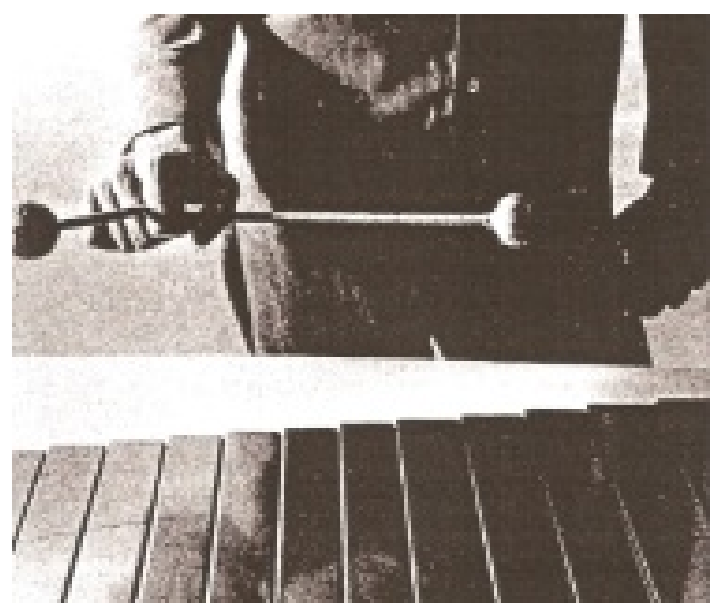

Figura 2.2.2. Burton grip. Fonte: Burton (1995, p. 10).

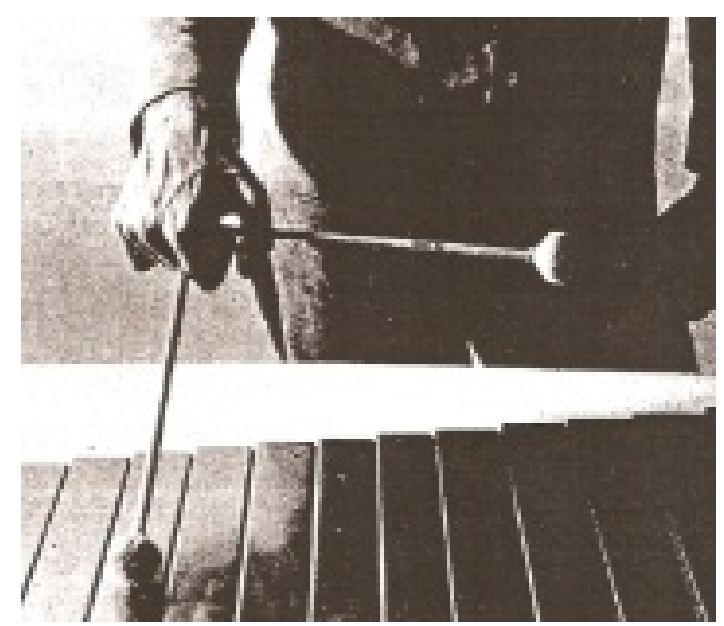

Figura 2.2.3. Burton grip. Fonte: Burton (1995, p. 10).

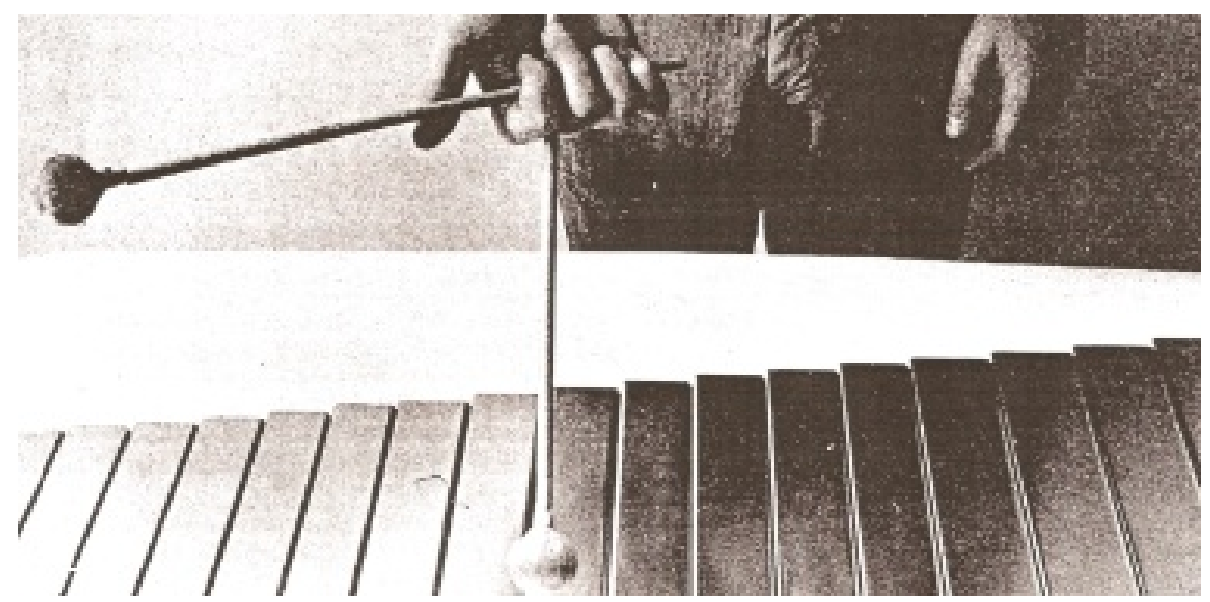

Figura 2.2.4. Burton grip. Fonte: Burton (1995, p. 11). 


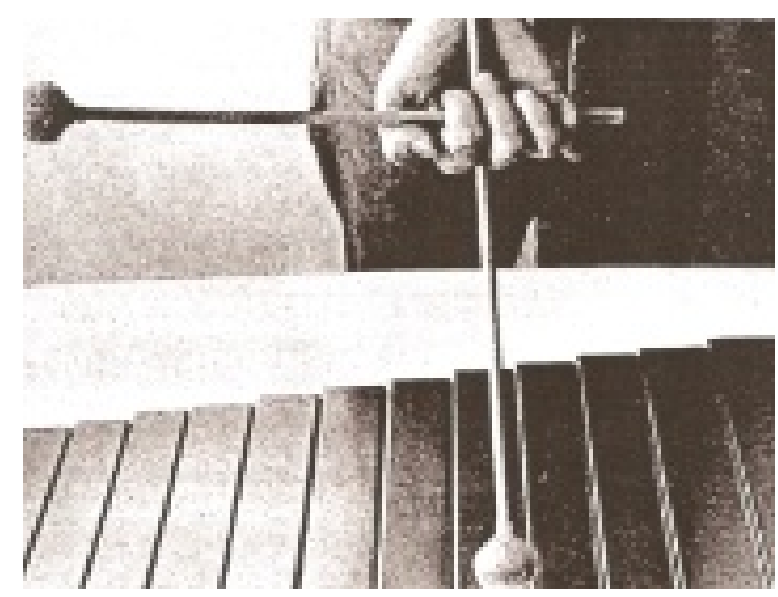

Figura 2.2.5. Burton grip. Fonte: Burton (1995, p. 11).

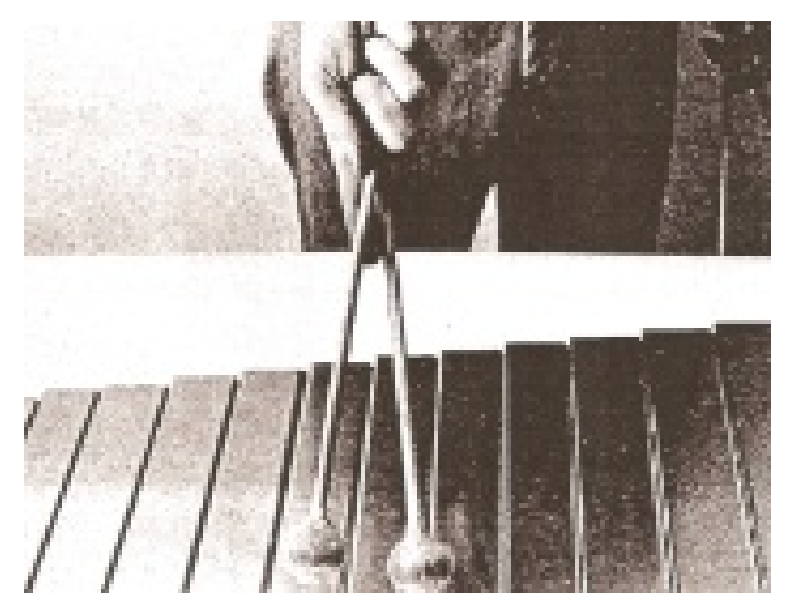

Figura 2.2.6: Burton grip. Fonte: Burton (1995, p. 11).

Dentre os grips mais comumente usados, Burton faz algumas críticas à Musser grip e à Tradicional grip:

Entre os grips mais comumente usados existem dois os quais eu critico de alguma forma. Um método é segurar as baquetas com dois dedos entre as baquetas (uma variação deste procedimento é chamado "Musser" grip). Minha crítica a esse método é que se torna impossível ou extremamente difícil fechar as baquetas inteiramente. E a execução de uma segunda maior e uma segunda menor somente pode ser obtida com um considerável movimento de rotação dos pulsos, o que gera a perda de liberdade e destreza. Outro grip frequentemente utilizado é aquele que usa um dedo entre as baquetas com a baqueta de dentro no topo ${ }^{13}$.Com este grip, linhas melódicas compostas de

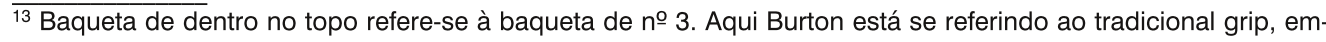
bora não mencione este termo.
} 
notas simples (single note lines) precisam ser tocadas com as duas baquetas de dentro, enquanto que as baquetas de fora permanecem para cima. Eu considero este procedimento inconveniente pelas duas razões seguintes: 1) Quando se toca com quatro baquetas, a baqueta de cima ${ }^{14}$ está conduzindo a linha melódica. Mudando-se para duas baquetas, a linha melódica passaria a ser executada pela segunda baqueta $^{15}$. Em passagens que requerem frequentes mudanças desta natureza, acarreta-se em perda de suavidade, porque a execução da linha melódica fica com muita alternância entre as duas baquetas de cima (mais ou menos como dois saxofonistas que trocam repetidamente as partes). Esta inconsistência limita a qualidade da fluência das linhas melódicas e complica o processo mental envolvido. 2) Quando se toca uma linha melódica com a baqueta de dentro da mão direita enquanto se segura a baqueta de fora acima do teclado, a baqueta de fora gera um excesso de peso e movimento. O tipo de movimento da mão deve então mudar do ataque vertical para o de rotação lateral, como o movimento de rulo de duas baquetas com uma mesma mão. Mais uma vez, passagens que requerem frequentes mudanças de duas para quatro baquetas causariam inconsistência nos ataques que ficariam limitadas em termo de uniformidade (BURTON, 1995, p. 3 e 4).

Para se ter certeza se a baqueta de fora está sendo segurada adequadamente, Howarth (2002, p.37) sugere um rápido teste: segurar as duas baquetas com a palma da mão para baixo e deixar cair a baqueta de fora. Se esta baqueta cair no chão, retornar aos passos iniciais novamente. Se a baqueta de fora for sustentada pela baqueta de dentro, significa que se está pronto para se seguir em frente.

\subsection{Grip utilizado por Ney Rosauro}

Num artigo escrito para a revista Percussive Notes em fevereiro de 1998, Rosauro descreve o grip por ele utilizado como sendo uma extensão do Burton grip, mas com certas modificações. Segundo o autor, após quinze anos tocando instrumentos de teclados de percussão, desenvolveu sua própria maneira de segurar as quatro baquetas:

Eu não estava satisfeito com o Burton Grip. Então comecei a combinar os melhores recursos de outros grips com a intenção de melhorar os três principais problemas técnicos deste grip: 1) o constante clic produzido pelos cabos de ratam na palma das mãos; 2) a falta de rotação de pulso para a realização de rulos com uma mão em pequenos intervalos; 3 ) a falta de opções para os rulos com quatro baquetas (ROSAURO, 1998, p.32).

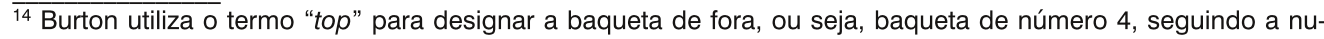
meração que convencionamos no início do artigo. Em seu método, Four Mallet Studies, Burton estabelece uma numeração para as baquetas em ordem contrária. Lembramos que os métodos consultados que utilizam a Burton grip, na grande maioria, métodos para vibrafone, costumam numerá-las desta forma.

15 Baqueta 3.

ouvirouver

Uberlândia v. 12 n. 1 p. $102-130$ jan.|jul. 2016
} 
De acordo com Rosauro, durante suas viagens por diversos países, encontrou vários outros executantes que também chegaram às mesmas soluções apresentadas por ele em seu artigo e que de forma instintiva teriam sido levados às mesmas conclusões para resolverem os problemas encontrados no Burton grip.

As proposições apresentadas por Rosauro ao Burton grip, com o intuito de torná-lo mais independente sem, no entanto, perder o seu potencial, são:

1. No que diz respeito à baqueta de fora: $O$ quarto dedo é o mais importante, pois ele sempre sustentará a baqueta. O final do cabo da baqueta deve ser colocado entre as duas metades da palma da mão. A junta do quarto dedo deve se curvar o mais que puder para que a ponta do dedo segure a baqueta. Esta baqueta deverá sempre ser segura com o quarto dedo e o ângulo formado entre a segunda e terceira partes deste dedo deverá ser próximo a 90 graus. O quarto dedo estará sempre curvado (Figura 2.3.1) (ROSAURO, 1998, p.32).

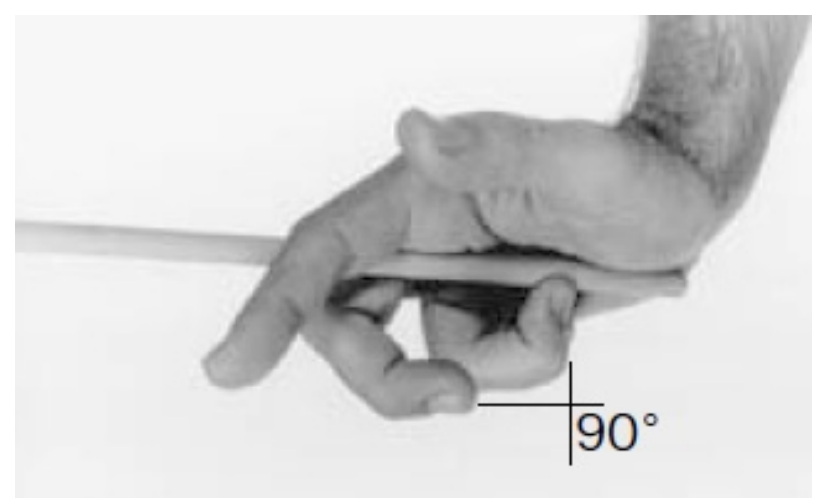

Figura 2.3.1. Mão direita de Rosauro com baqueta externa. Fonte: Rosauro (1998, p. 32).

2. No que diz respeito à baqueta interna: esta baqueta será presa basicamente pelo quinto dedo. Este dedo deve se curvar em torno do cabo da baqueta e sua ponta deve sempre estar em contato com a palma da mão. Isto dará liberdade à baqueta para movimentar-se para cima e para baixo (Figura 2.3.2) (ROSAURO, 1998, p.32).

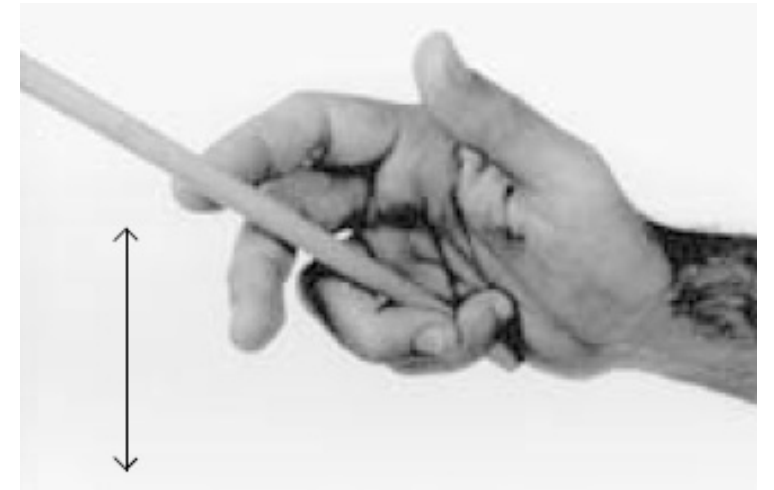

Figura 2.3.2. Mão direita de Rosauro com baqueta interna. Fonte: Rosauro (1998, p. 32). 
De acordo com Rosauro, os cabos das baquetas se cruzam na palma da mão e o quinto dedo se curva sobre o cabo da baqueta de fora com a ponta do dedo tocando a palma da mão. Diferentemente do Burton grip, a baqueta de fora não deve ser segurada com o terceiro dedo. Desta forma, os cabos não tocam na palma da mão, evitando o clic característico resultante do contato dos cabos. Com este grip também se adquire maior independência entre as baquetas. $O$ terceiro dedo tem pouca coisa a realizar, ficando apenas apoiado sobre a baqueta de dentro e ajudando a suportar o peso em conjunto com o quarto e quinto dedo (Figura 2.3.3).

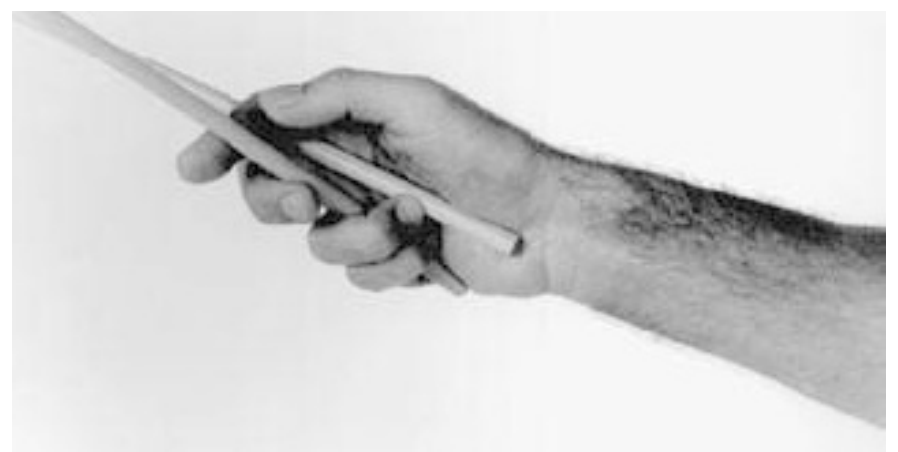

Figura 2.3.3. Mão direita de Rosauro evidenciando a posição do quarto dedo. Fonte: Rosauro (1998, p. 32).

Para Rosauro, a maneira mais fácil e sem tensão para começar a aprender este grip é com os intervalos de quarta ou quinta (Figura 2.3.4).

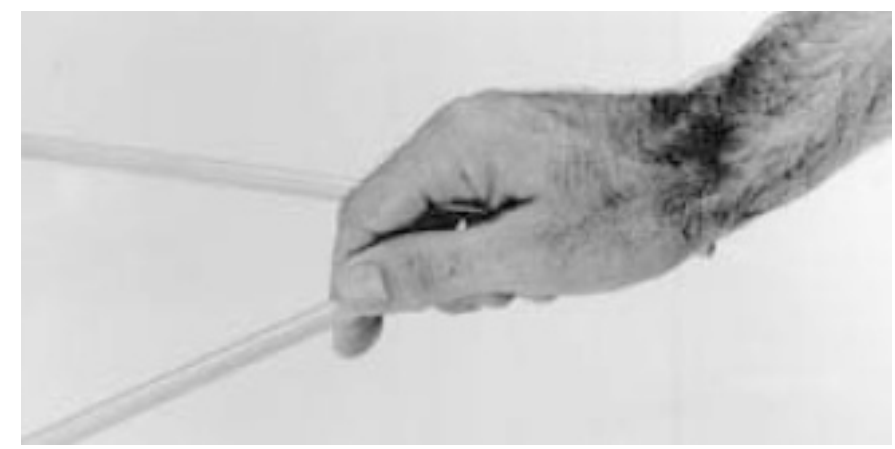

Figura 2.3.4. Mão direita de Rosauro com baqueta em posição para intervalos de quartas e quintas. Fonte: Rosauro (1998, p. 32).

Para as mudanças de intervalos entre as baquetas, Rosauro explica que a baqueta de dentro é movida pelo segundo dedo e pelo polegar. O segundo dedo é usado para abrir os intervalos e o polegar para fechá-los. Rosauro também adverte para que se tenha certeza de que os dedos estejam relaxados e naturalmente curvados, sem nenhuma tensão extra para se manter as baquetas nas mãos. 


\subsection{Gordon-Stout grip}

Neste método de se segurar quatro baquetas, conhecido com GordonStout ${ }^{16}$ grip, descrito por Kostowa e Giesecke (1996, p. 7), as baquetas são seguradas da seguinte maneira: a baqueta de fora (número 4) é fixa entre o terceiro e quarto dedos. De acordo com os autores, todos os outros detalhes são idênticos à Burton/Friedman/Samuels grip (Figura 2.4.1).

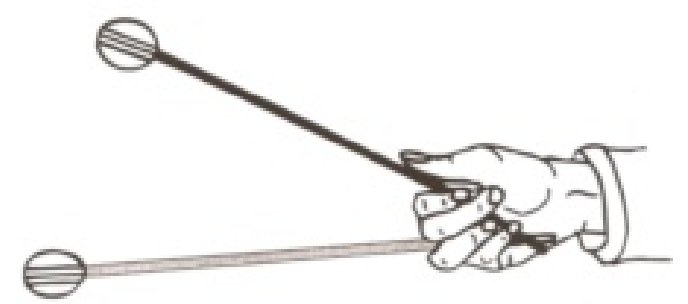

Figura 2.4.1. Gordon-Stout grip. Fonte: Kostowa/Giesecke (1996, p. 7).

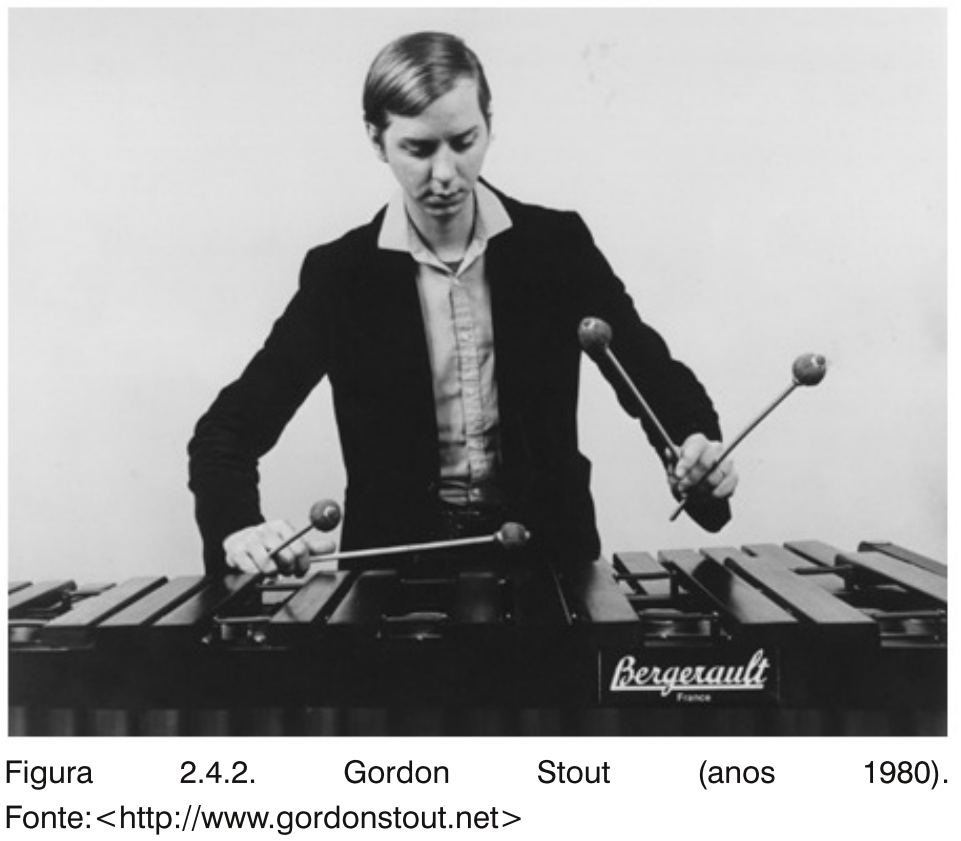

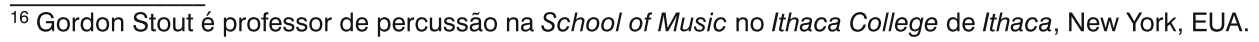




\subsection{Fulcrum ${ }^{17}$ grip}

De acordo com Ed Saindon ${ }^{18}$ (2008, p.46-47), este é um grip para quatro baquetas, usado tanto para o vibrafone como para a marimba, que incorpora controle dos dedos em conjunto com os movimentos do pulso e do braço. Este controle dos dedos é realizado através de um ponto de apoio (fulcrum point) semelhante ao usado no grip de duas baquetas. Segundo o autor, quando o percussionista utiliza duas baquetas nos teclados, geralmente o faz do mesmo modo como segura as duas baquetas de caixa clara. Ou seja, a baqueta é presa entre o polegar e o dedo indicador (fulcrum/pinça), enquanto que os outros dedos são usados para gerar o movimento da baqueta de se aproximar ou se afastar da palma da mão. Com o fulcrum grip, aplica-se o mesmo princípio. Para o autor, este grip proporciona o melhor dos dois contextos: a destreza e força que se tem no uso de duas baquetas como também a habilidade para utilizar todas as quatro baquetas.

Neste grip existem dois pontos de apoio. Estes pontos dependem das aberturas dos intervalos entre as baquetas. Saindon comenta que é importante mencionar que em ambos os pontos de apoio, as baquetas saem do contato com a palma da mão através do rápido movimento dos dedos.

Para aberturas das baquetas que compreendem intervalos pequenos e médios o ponto de apoio fica entre o terceiro dedo e o polegar (Figuras 2.5.1 e 2.5.2). A ponta do terceiro dedo fica em contato com a baqueta de fora para controlá-la e mantê-la na palma da mão enquanto que o polegar e o segundo dedo ficam esticados. O terceiro dedo permite que a baqueta de dentro saia da palma da mão empurrando-a de volta para a palma de mão. Quando se usa a baqueta de fora, o quarto dedo é também usado para empurrar a baqueta de volta para a palma da mão.

A baqueta de dentro realiza um movimento descendente como se fosse uma extensão do antebraço.

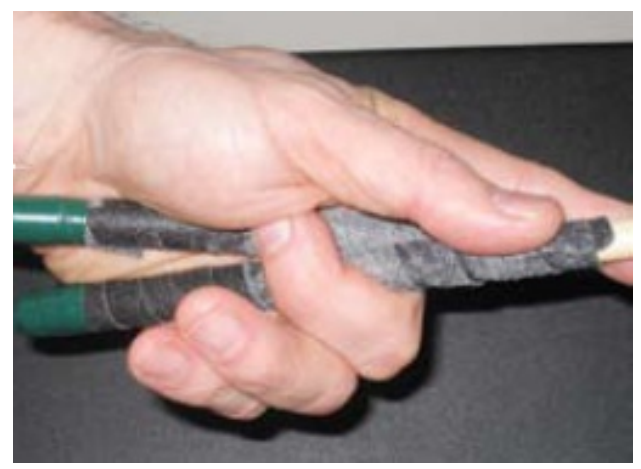

Figura 2.5.1. Visão do grip por Ed Saindon para intervalos pequenos e médios. Fonte: Saindon (2008, p. 46).

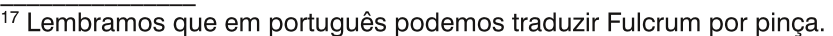

18 Desde 1976, Ed Saidon é professor na Berklee College of Music, em Boston, Massachussets (EUA). Além de professor é ainda interprete com inúmeras gravações e pesquisador com diversas publicações. 


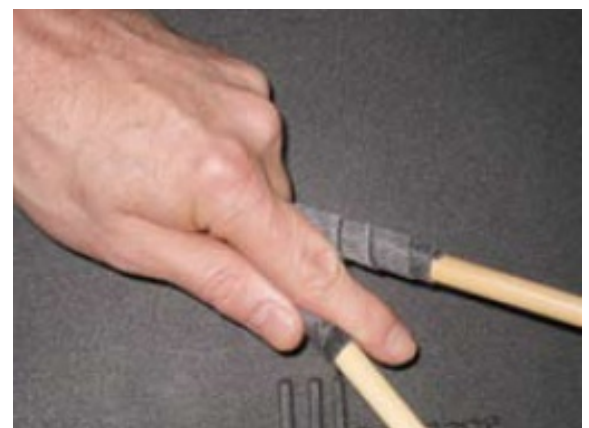

Figura 2.5.2. Visão do grip para intervalos pequenos e médios. Fonte: Saindon (2008, p. 46).

Para as aberturas das baquetas que compreendem de intervalos médios a grandes, o ponto de apoio fica entre o polegar e a primeira junta do segundo dedo, como na matched grip ${ }^{19}$ de caixa clara (Figuras 2.5 .3 e 2.5.4). Neste caso, o terceiro dedo não direciona a baqueta de fora para a palma de mão, mas sim, permite que esta baqueta saia da palma da mão e forme um ângulo quase perpendicular com o antebraço. Com o polegar e o segundo dedo atuando como o ponto de articulação, o terceiro, quarto e quinto dedos são usados para empurrar a baqueta de dentro na direção da mão. As baquetas de dentro e de fora formam o desenho de um triângulo, com a baqueta de fora quase perpendicular ao antebraço. Quando se toca com a baqueta de fora, utiliza-se um movimento de antebraço intencional.

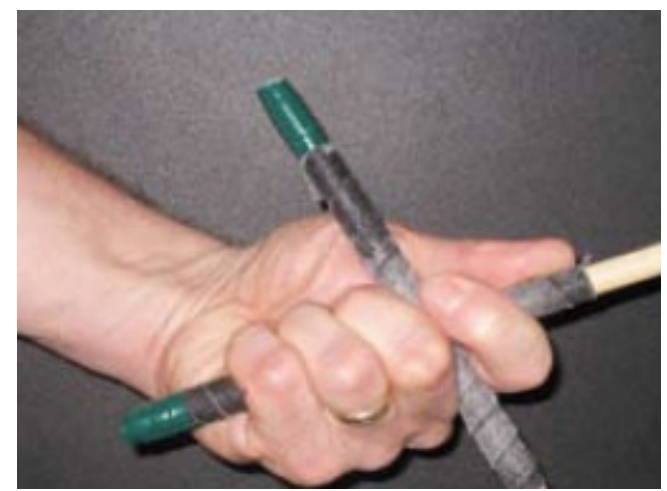

Figura 2.5.3. Visão do grip em intervalos médios e largos. Fonte: Saindon (2008, p. 46).

\footnotetext{
${ }^{19}$ Matched grip: grip empregado para duas baquetas que tem a pinça entre o polegar e a primeira junta do segundo dedo. Pode ser compreendido como universal grip. 


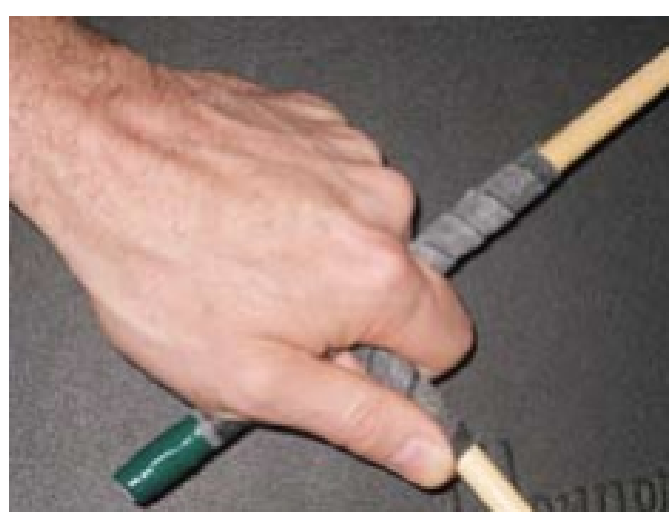

Figura 2.5.4. Visão do grip para intervalos médios e largos. Fonte: Saindon (2008, p. 46).

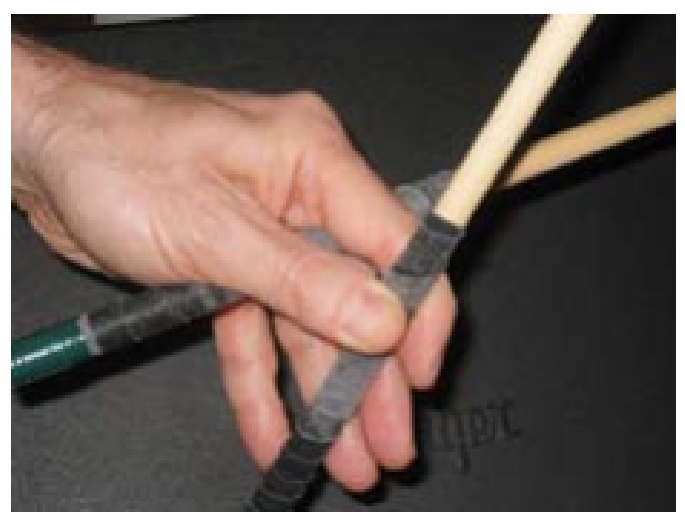

Figura 2.5.5. Visão do grip com a baqueta longe da palma de mão e pronta para ser puxada (snapped back) de volta pelos dedos. Fonte: Saindon (2008, p. 46).

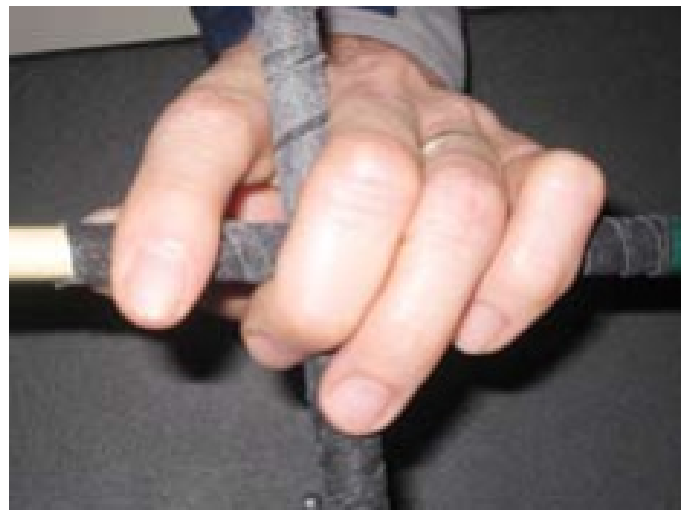

Figura 2.5.6. Visão do grip com a baqueta de fora longe da palma da mão e pronta para ser puxada de volta pelo quarto dedo. Fonte: Saindon (2008, p. 46). 
De acordo com Saindon ${ }^{20}$ este grip é uma extensão do Burton grip. Funciona tanto para marimba como para vibrafone. Foi desenvolvido pelo próprio autor e o objetivo central deste grip é utilizar as quatro baquetas com destreza equivalente entre elas.

\subsection{Musser Grip}

Clair Omar Musser foi uma figura de relevância incontestável para o desenvolvimento da marimba em todos os seus aspectos e também foi quem desenvolveu este grip, que acabou sendo denominado com o seu nome.

Neste grip os cabos das baquetas não se cruzam. A baqueta de número 4, que é a baqueta que fica do lado externo em relação ao corpo, é presa pelos dedos de número 5 e 4 . Segundo Chenoweth, estes dedos possuirão poucos movimentos, até que grande proficiência seja adquirida ${ }^{21}$ (Figura 2.6.1).

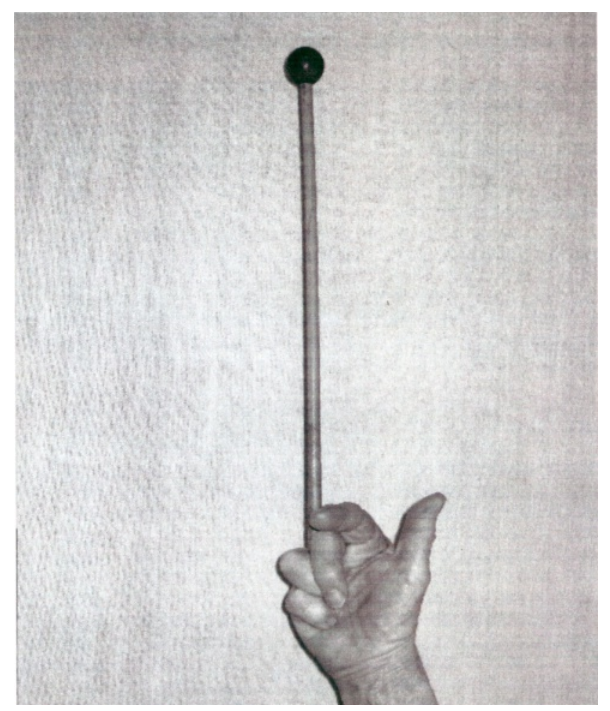

Figura 2.6.1. Mão direita de Vida Chenoweth com a baqueta externa (Musser grip). Fonte: da autora ${ }^{22}$.

Observa-se a outra baqueta, que corresponde à baqueta 3 e que fica do lado interno em relação ao corpo, é presa pelo polegar e pelo indicador. Ela é presa exatamente do modo como se segura apenas uma baqueta na mão, entre o dedo indicador e polegar. Esta baqueta, segundo Chenoweth, possui mais liberdade de movimento de um lado para outro, para realizar assim o trabalho de atingir diferentes aberturas intervalares (Figura 2.6.2).

\footnotetext{
${ }^{20}$ Entrevista realizada por e-mail em 01/07/2010.

${ }_{21}$ Foto a nós enviada pela própria Vida Chenoweth (em carta datada a 2 de setembro de 2008).

${ }^{22}$ As figuras de 2.6.1 a 2.6.4 mostram a mão direita de Vida Chenoweth. Todas estas fotos nos foram enviadas por Chenoweth em carta datada a 2 de setembro de 2008.
} 


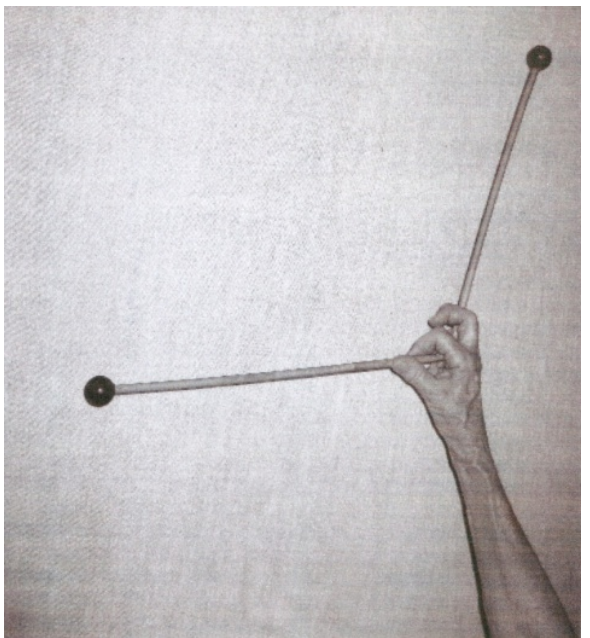

Figura 2.6.2. Mão direita de Chenoweth, abertura para intervalo amplo (Musser grip). Fonte: da autora.

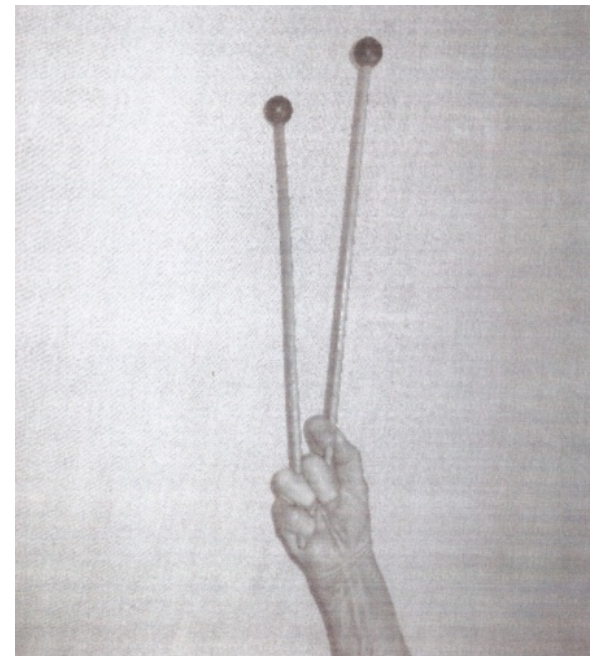

Figura 2.6.3. Mão direita de Chenoweth, abertura para intervalo menos amplo (Musser grip). Fonte: da autora.

Pelo fato da baqueta externa ser segurada ligeiramente acima do final do cabo, nota-se que a cabeça da baqueta interna fica mais longe da mão do que a cabeça da baqueta externa. Isto faz com que a baqueta de dentro pareça mais longa que a de fora (Figura 2.6.4). 


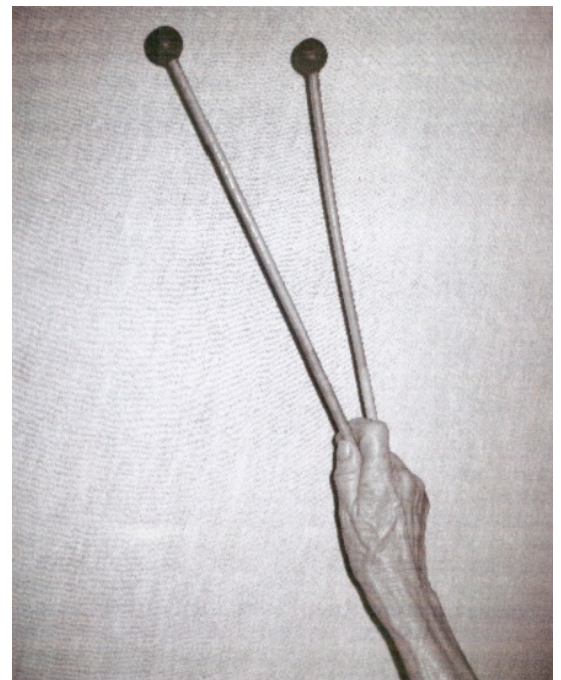

Figura 2.6.4. Mão direita de Chenoweth, visão do Musser grip. Fonte: da autora.

De acordo com Chenoweth, o Musser grip pode parecer desconfortável no início, mas paciência é chave do sucesso:

\begin{abstract}
O Musser grip, por outro lado de início é desconfortável e muitas vezes surgem dores. No entanto, com a devida perseverança, os músculos dos dedos e do antebraço podem ser desenvolvidos de forma que o grip seja naturalmente acomodado. Deve-se enfatizar que nem a proficiência nem o conforto deverão ser esperados em menos de um ano ou mais, e é ainda inútil prejudicar os músculos ou danificar a pele entre os dedos. Paciência é a palavra-chave, e quando os dedos ou os braços começarem a doer, é aconselhável mudar o estudo para duas baquetas ou parar temporariamente. Tais intervalos entre as práticas são benéficos e podem ser aproveitados para estudos de memorização fora do instrumento ou no piano (CHENOWETH, 1963, p.5).
\end{abstract}

No Musser grip, de acordo com Chenoweth, a posição das mãos em relação ao teclado, as palmas das mãos geralmente ficam voltadas para baixo com a parte superior totalmente para cima, o que é comum para acordes em posição fechada. Quando se utilizam bemóis ou sustenidos, esta posição se modifica ligeiramente.

\title{
2.7 Stevens grip
}

Leigh Howard Stevens (1977), descreve a maneira desenvolvida por ele para o uso das quatro baquetas. Embora o autor tenha usado todas as três técnicas descritas neste capítulo (tradicional, Musser e Burton grips) por diversos anos e tenha experimentado melhorias a cada mudança de grip, ele não recomenda nenhuma delas para solos em marimba (STEVENS, 1993, p. 9). 
O grip utilizado pelo autor é derivado do Musser grip, mas este grip não se assemelha ou opera como a família dos Musser grips descritos em vários métodos de percussão em geral. As principais diferenças estão relacionadas às áreas da posição da mão (postura), operações mecânicas e à área e método de se segurar o cabo da baqueta (STEVENS, 1993, p. 8).

As diferenças entre o Musser grip e o Stevens grip são também apontadas por Chenoweth:

Com relação ao Musser Grip: geralmente as palmas das mãos apontam para baixo, com as juntas dos dedos para cima. Isto é comum para acordes em posição fechada. Quando ocorrem acidentes (bemóis ou sustenidos), o posicionamento se modifica levemente. Da maneira ensinada por Musser, os polegares não ficam para cima - este foi um hábito desenvolvido por Stevens por não controlar o rulo de quatro notas mantendo o nível de suas mãos equiparados com o teclado. Por essa razão ele teve que girar seus pulsos, outro ponto que não era ensinado por Musser porque a sua técnica não necessitava deste recurso (CHENOWETH) ${ }^{23}$.

A próxima ilustração extraída de seu livro, Method of Movement for marimba (Figura 2.7.1), exemplifica o Stevens grip:

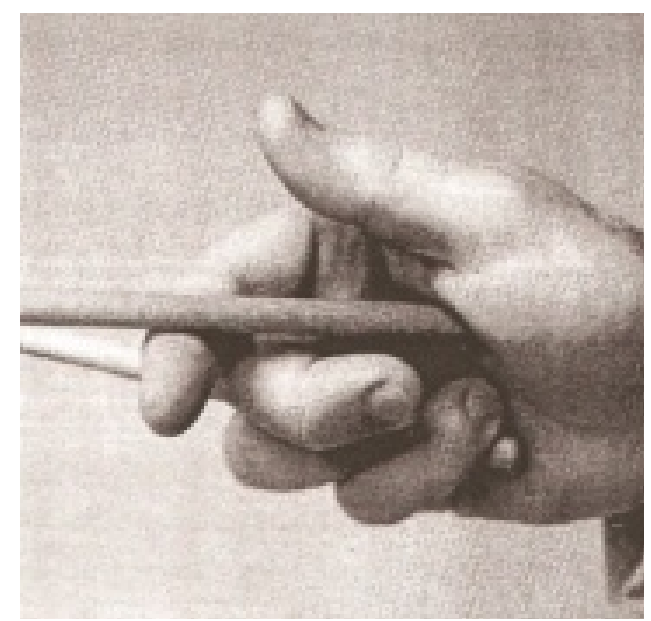

Figura 2.7.1. Stevens grip. Fonte: Stevens (1993, p. 10).

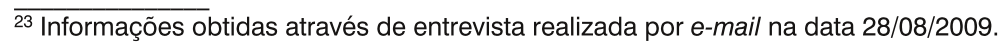




\subsection{Mainieri grip}

Citada por Kostowa e Giesecke, (1996) neste grip as baquetas de fora são fixadas entre os dedos de número 4 e 5 . A baqueta de dentro é presa pelos dedos 1, 2 e 3 (Figura 2.8.1).

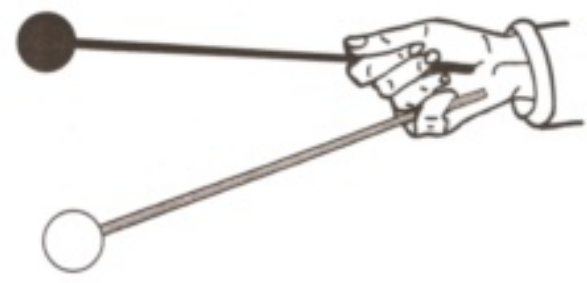

Figura 2.8.1. Mainieri grip. Fonte: Kostowa/Giesecke (1996, p. 11).

Neste grip o dedo mínimo exerce uma pressão no cabo da baqueta, estabilizando-a, e facilitando ainda a realização de rulos com as baquetas de dentro através do polegar e dedo indicador, bem como uso de aberturas intervalares de segundas menores.

\section{Considerações finais}

Os autores consultados concordam entre si sobre as descrições realizadas a respeito dos diferentes grips, mas observou-se que com relação aos nomes empregados para estes grips surgiram algumas divergências. Um mesmo grip apresenta diferentes nomes. Como exemplos temos o tradicional grip que é conceituado por alguns autores como Delecluse grip, cross grip e cross stick no 2. Já o Burton grip também vem sendo conceituado por cross stick no 1. Por fim, o Stevens grip vem sendo conceituado também por Musser/Stevens grip. Ou seja, temos nomes diversos para uma mesma coisa.

$\mathrm{Na}$ opinião de Chenoweth ${ }^{24}$, o Stevens grip é o Musser grip, tratando-se, portanto do mesmo grip. Segundo a autora, este grip foi ensinado a Stevens por ela. Para Chenoweth, todos os outros grips, independentemente de quem as usam ou a quem o nome se encontra atrelado, resumem-se no cross hammer grip, ou seja, grip com cabos cruzados, que remonta ao final dos anos 30 do século passado. Por outro lado, vimos que diversos autores conceituam o grip utilizado por Stevens, como sendo um grip propriamente dito, dada as modificações ocorridas em relação ao Musser grip. Vimos também, que embora sendo uma extensão do Burton grip, Ed Saindon, denomina o grip desenvolvido por ele pelo nome de Fulcrum grip.

Portanto, uma vez que estes grips se conceituam de forma mais pontual, podemos também considerar a existência do Rosauro grip. É certo que se trata de um grip derivado do Burton grip, mas com consistentes alterações, suficientes mesmo para considerá-lo como um novo grip propriamente dito. No artigo elaborado à

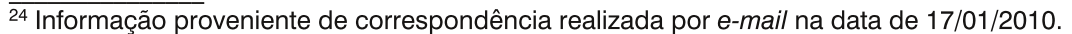


Percussive Arts Society (1998, p. 32), Rosauro não utiliza o termo Rosauro grip. O autor considera o grip por ele utilizado como uma extensão ou uma versão modificada do Burton grip, com emprego de movimentações provenientes da técnica Stevens. Mas, uma vez constatadas estas modificações que são teorizadas pelo autor, concluímos que podemos conceituá-lo com um nome mais pontual, uma vez que o autor possui uma carreira com projeção internacional, difundindo assim o grip por ele utilizado e evidenciando com clareza os procedimentos utilizados.

Enfatizando esta afirmação, de acordo com Liao (2005, p.62), podem-se apontar duas importantes diferenças entre o Burton grip e a versão modificada de Rosauro. Primeiro, ao invés de se ter as palmas das mãos voltadas para baixo, Rosauro sugere uma posição mais natural com as palmas das mãos ligeiramente inclinadas, o que é uma influência do Stevens grip. Segundo o autor, as duas baquetas em cada mão não se tocam. Para isso, Rosauro sugere segurar a baqueta de fora com a primeira parte do quarto dedo. Cada junta do quarto dedo deverá formar um ângulo de aproximadamente 90 graus. Corroborando esta ideia, vimos que os nomes empregados foram dados por intérpretes consagrados que difundiram efetivamente o uso de determinados grips. Isto facilita a conceituação dos termos bem como a didática do instrumento, em especial no Brasil, onde o Rosauro grip é muito difundido.

Portanto, partindo do pensamento acima colocado e enfatizando o conceito de grip, propomos uma tabela final contendo, em nossa opinião, oito tipos diferentes de grips.
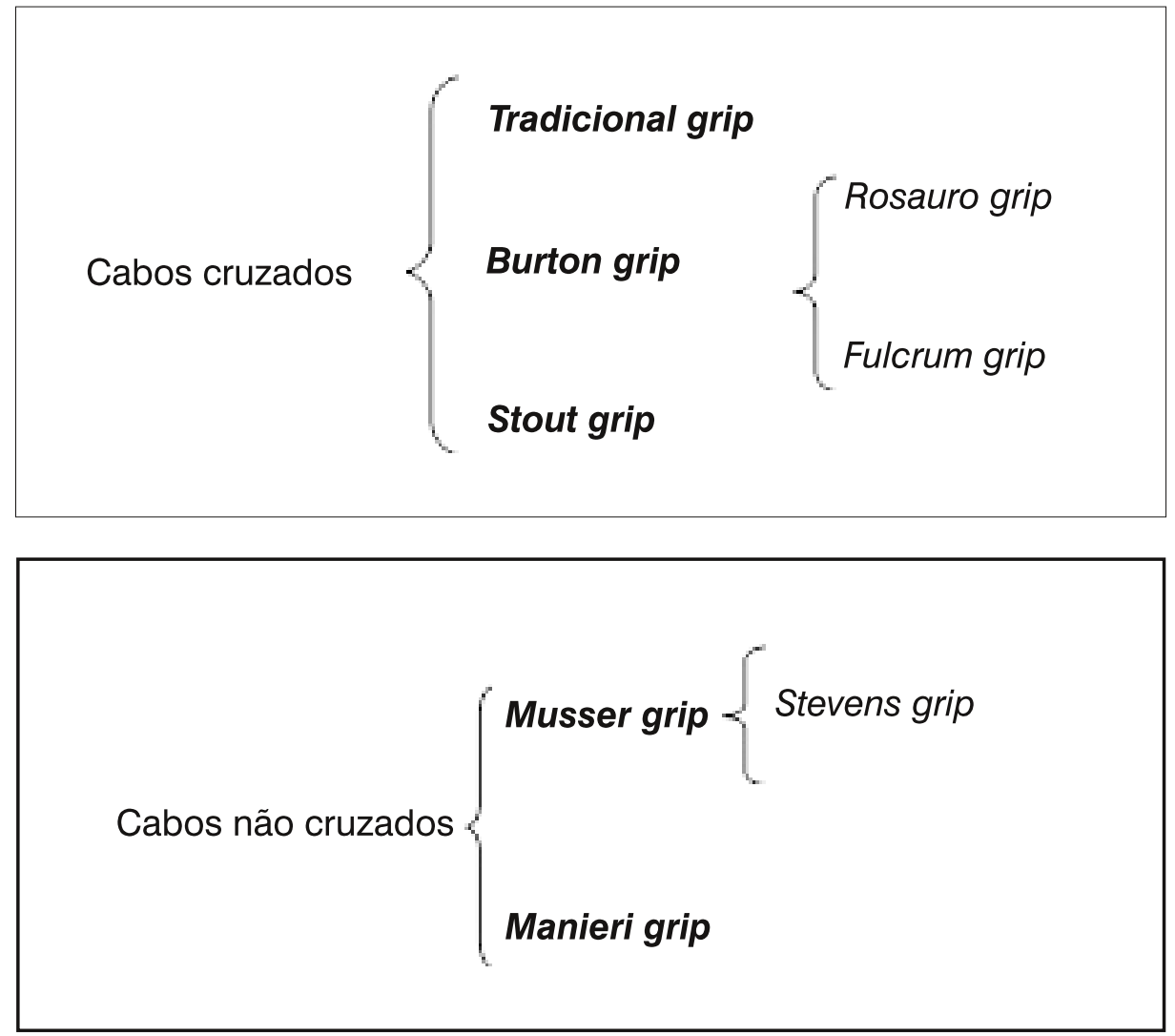
O Rosauro grip e o Fulcrum grip são derivados do Burton grip e o Stevens grip, derivado do Musser grip, ou seja, são versões modificadas destes dois grips anteriores.

Lembramos mais uma vez que a escolha do grip a ser utilizado depende de particularidades da anatomia da mão de cada indivíduo, portanto é natural que existam grips que melhor se adaptem a diferentes mãos. O importante é que, independente do grip utilizado, não haja tensão nos dedos e braços e o executante tenha um toque confortável e relaxado.

\section{Referências}

BECK, John. Encyclopedia of Percussion. New York: Garland, 1995.

BURTON, Gary. Evolution of Mallet Techniques. Percussionist. v.10, n.3, spring, 1973, p.74-82.

Four Mallets Studies. USA: Glenview, Illinois. Creative Music, 1995.

CHENOWETH, Vida. Defining the Marimba and Xylophone Inter-culturally. Percussionist, v.1, n.1, 1963, p.4-6. 4 mallet Technique. Percussionist, December / 1963.

GLASSOCK, Lynn. Four-Mallet Grips - Percussive Notes, Fall, 1973, p.2-11.

HOWARTH, Gifford. Simply Four 4 - Mallet Technique as easy as 1-2-3...4.

KITE, Rebecca. Keiko Abe. A Virtuosic Life. GP Percussion, 2007.

The Marimba in Carnegie Hall and Town Hall from 1935-62. Percussive Notes, August 2005, p.50-54.

KOSTOWA, Wessela / GIESECKE, M. Andreas. Compendium of 4-Mallet-techniques for Vibraphone, Marimba and other Percussion Instruments. Frankfurt am Main, Zimmermann, 1996.

LIAO, Wan-Chun. Ney Rosauro's two Concerti for Marimba and Orchestra: Analysis, Pedagogy and Artistic Considerations (Dissertação de Doutorado). University of Miami, 2005.

MERRILL, Greg. The Marimba. Scientific Aspects of its Construction and Performance: an exhaustively researched study, 1996 (Disponível em http://faculty.smu.edu/ttunks/projects/merrill/MarimbaH.html - acesso a 23 de abril de 2010).

PETERS, Mitchell. Fundamental Method for Mallets. Alfred Publishing, 1975.

ROSAURO, Ney. Crossing Grip Extensions. Percussive Notes, February, 1998, p.32-35.

SAINDON, Ed. The Fulcrum Grip. Percussive Notes, December 2008, p.46-47. 
STEVENS, Leigh Howard. An Interwiew With Vida Chenoweth. Percussive Notes, Spring/Summer, 1977.

Method of Movement for Marimba. New Jersey: Keyboard Percussion Publications, 1993 [1a ed.1979].

STOUT, Gordon. Ideo-Kinetics, A Workbook for Marimba Technique. New York: M. Baker, 1993.

SULPICIO, Eliana C. M. G. O Desenvolvimento da Técnica de Quatro Baquetas: dos primórdios às primeiras composições brasileiras. Tese de Doutorado, 2011. ECA-USP.

TACHOIR, Jerry. Contemporary Mallet Method - An Approach to the Vibraphone \& Marimba. Hendersonville, Riohcat Music, 1991.

TARCHA, Carlos. Técnica de Duas Baquetas para Teclado de Percussão - Marimba, Vibrafone, Xilofone e Glockenspiel. São Paulo (Dissertação de Mestrado). São Paulo, ECA-USP, 1997.

ZELTSMAN, Nancy. Four-Mallet Marimba Playing. A Musical Approach for All Levels. Hall Leonard Corporation, 2003. 